\title{
Leptin-dependent platelet aggregation and arterial thrombosis suggests a mechanism for atherothrombotic disease in obesity
}

\author{
Stavros Konstantinides, Katrin Schäfer, Stefan Koschnick, and David J. Loskutoff \\ Department of Vascular Biology, The Scripps Research Institute, La Jolla, California, USA \\ Address correspondence to: David J. Loskutoff, Department of Vascular Biology, The Scripps Research Institute, \\ 10550 North Torrey Pines Road (VB3), La Jolla, California 92037, USA. \\ Phone: (858) 784-7125; Fax: (858) 784-7353; E-mail: loskutof@scripps.edu. \\ Stavros Konstantinides and Katrin Schäfer's present address is: University of Göttingen, Department of Cardiology, \\ Göttingen, Germany.
}

Stavros Konstantinides and Katrin Schäfer contributed equally to this work.

Received for publication April 27, 2001, and accepted in revised form September 24, 2001.

\begin{abstract}
Obesity is associated with increased cardiovascular morbidity and mortality and with elevated circulating levels of the satiety factor leptin. This study provides evidence for a direct link between leptin and the risk for thrombotic complications in obese individuals. For example, although arterial injury provokes thrombosis in both lean and obese $(o b / o b)$ mice, the time to complete thrombotic occlusion is significantly delayed in the $o b / o b$ mice, and the thrombi formed are unstable and frequently embolize. The $o b / o b$ mice lack leptin, and intraperitoneal administration of leptin to these mice before injury restores the phenotype of lean mice by shortening the time to occlusion, stabilizing the thrombi, and decreasing the patency rate. The thrombi that form when leptin receptor-deficient obese $(d b / d b)$ mice are injured also are unstable. However, in this instance, leptin has no effect. Platelets express the leptin receptor, and leptin potentiates the aggregation of platelets from $o b / o b$ but not $d b / d b$ mice in response to known agonists. These results reveal a novel receptor-dependent effect of leptin on platelet function and hemostasis and provide new insights into the molecular basis of cardiovascular complications in obese individuals. The results suggest that these prothrombotic properties should be considered when developing therapeutic strategies based on leptin.
\end{abstract}

J. Clin. Invest. 108:1533-1540 (2001). DOI:10.1172/JCI200113143.

\section{Introduction}

Obesity is associated with accelerated atherothrombosis and an increased incidence of cardiovascular morbidity and mortality. Numerous observations suggest that it is the interplay of the metabolic disorders that frequently accompany excess body weight (e.g., insulin resistance, hyperinsulinemia, hypertension, hypertriglyceridemia, and decreased HDL cholesterol), that promote the progression of atherosclerotic lesions in obese individuals $(1,2)$. However, it is also possible that altered hemostatic balance in the circulation may contribute to the pathogenesis of acute cardiovascular events in such patients $(3,4)$. The latter hypothesis has prompted a search for circulating factors that may be responsible for the enhanced thrombotic response to vascular injury of obese individuals.

Leptin, the 167-amino acid product of the $o b$ gene, is a major regulator of fat and energy storage in mammals (5). It is synthesized primarily in adipocytes and acts on hypothalamic receptors to reduce food intake and increase energy expenditure by modulating glucose and fat metabolism (6). The $o b / o b$ mouse lacks the functional form of leptin because of a nonsense mutation in codon 105 of the $o b$ gene and, as a consequence, develops severe hyperphagia and excessive obesity $(5,7)$. Administration of leptin to these mice not only results in rapid weight reduction, but also corrects the metabolic abnormalities (8). Although leptin deficiency in humans may also lead to obesity (9), such individuals are rare. In fact, obese humans often have elevated circulating levels of leptin $(10,11)$ because they develop resistance to its weight-reducing effects (6).

Recent observations suggest that leptin has a much broader biological role than the regulation of body weight. For example, leptin was reported to regulate immune function (12), angiogenesis (13), bone formation (14), and fertility (15), and expression of the leptin receptor was demonstrated in a variety of tissues $(16,17)$. Interestingly, the long form of the leptin receptor was detected in human platelets (18), and high concentrations of leptin were reported to act synergistically with ADP to promote platelet aggregation in vitro. These latter observations raise the possibility that leptin also may promote thrombosis and contribute to disorders of hemostatic balance in obesity. To test this hypothesis in vivo, we 
employed the ferric chloride $\left(\mathrm{FeCl}_{3}\right)$ model of carotid artery injury $(19,20)$ to study arterial thrombosis in wild-type (WT) mice, in leptin-deficient $o b / o b$ mice, and in leptin receptor-deficient $d b / d b$ mice. We show that upon arterial injury with $\mathrm{FeCl}_{3}, o b / o b$ mice develop unstable thrombi and, as a consequence, have prolonged times to complete occlusion and an accelerated patency rate compared with WT mice. Intraperitoneal administration of recombinant murine leptin corrects these defects. These prothrombotic effects of leptin reflect a leptin receptor-mediated increase in the sensitivity of platelets to known platelet agonists (e.g., ADP) and possibly to other hemostatic factors.

\section{Methods}

Animals. WT (C57BL/6J), ob/ob (C57BL/6J-Lep $\left.{ }^{\mathrm{ob}}\right)$, and $d b / d b\left(\mathrm{C} 57 \mathrm{BL} / 6 \mathrm{~J}-\mathrm{m}+/+\right.$ Lepr $\left.^{\mathrm{db}}\right)$ mice were purchased from The Jackson Laboratories (Bar Harbor, Maine, USA). Animals were anesthetized by intraperitoneal injection of pentobarbital (Nembutal; $60 \mathrm{mg} / \mathrm{kg}$ ) and inhalation of methoxyflurane (Metofane; ScheringPlough Animal Health Corp., Union, New Jersey, USA) adjusted to maintain a respiratory rate of $60-80$ breaths $/ \mathrm{min}$. All animal care and experimental procedures complied with the Guide for Care and Use of Laboratory Animals, Department of Health, Education and Welfare, and were approved by the Animal Research Committee of the Scripps Research Institute.

Carotid injury and thrombosis. Male WT, ob/ob, and $d b / d b$ mice, 6-9 weeks old, were subjected to carotid artery injury using $\mathrm{FeCl}_{3}$ as described previously (19, $20)$. Briefly, the left carotid artery of the anesthetized mouse was carefully exposed by blunt dissection, and a $0.5 \times 1.0-\mathrm{mm}$ strip of Whatman no. 1 filter paper soaked in $10 \% \mathrm{FeCl}_{3}$ solution was applied to the surface of the vessel for 3 minutes. Carotid blood flow was monitored before and over a 25 -minute period after the injury as described (19), and complete thrombotic occlusion was considered to occur when flow decreased to $0.0 \pm 0.2 \mathrm{ml} / \mathrm{min}$. In some experiments, recombinant murine leptin (Peprotech Inc., Rocky Hill, New Jersey, USA); endotoxin content $<0.1 \mathrm{ng} / \mu \mathrm{g}$ leptin) was administered to the mice before injury as indicated in the text.

Glucose, insulin, and leptin levels in serum. Serum glucose was determined enzymatically using the hexokinase method (Sigma Diagnostics, St. Louis, Missouri, USA), while serum insulin concentrations were measured using a monoclonal anti-rat insulin enzyme-linked immunoassay (Crystal Chem Inc., Chicago, Illinois, USA). Leptin levels in serum were determined by two specific anti-murine leptin enzyme-linked immunoassays (R\&D Systems Inc., Minneapolis, Minnesota, USA, and Diagnostic Systems Laboratories Inc., Webster, Texas, USA, respectively). ELISAs were performed in duplicate for each sample.

Platelet preparation. Human platelets were prepared by standard procedures using blood anticoagulated with acid dextrose. To isolate murine platelets, anti- coagulated blood was collected from anesthetized mice by cardiac puncture with a 25 -gauge needle. Blood was pooled from five to six animals for each experiment. It was centrifuged at $150 \mathrm{~g}$ for 15 minutes at room temperature, and the platelet-rich plasma (PRP) layer was carefully removed. Platelets were counted in a spectrophotometer at $800-\mathrm{nm}$ wavelength, diluted with Tyrodes's buffer (5 mM HEPES, $2 \mathrm{mM} \mathrm{MgCl}_{2}, 0.1 \% \mathrm{BSA}$, and $0.1 \%$ D-glucose) to a standard concentration of $3 \times 10^{8} / \mathrm{ml}$ and immediately employed for the aggregation experiments using ADP. To obtain washed platelets for aggregation studies with thrombin, $1 \mu \mathrm{M}$ prostaglandin $\mathrm{E}_{1}$ and $1 \mathrm{U} / \mathrm{ml}$ apyrase were added to PRP, and the mixture was centrifuged for 15 minutes at $500 \mathrm{~g}$. The supernatant (platelet-poor plasma [PPP]) was removed, and the platelet pellet was gently resuspended in 1,4-piperazinediethanesulfonic acid (PIPES) saline buffer $(0.15$ $\mathrm{M} \mathrm{NaCl}$ and $20 \mathrm{mM}$ PIPES, $\mathrm{pH}$ 6.5) containing apyrase $(1 \mathrm{U} / \mathrm{ml})$ and prostaglandin $\mathrm{E}_{1}(5 \mu \mathrm{M})$, and centrifuged at $500 \mathrm{~g}$ for 15 minutes. The pelleted platelets were resuspended in Tyrode's buffer, count$\mathrm{ed}$, and diluted to a concentration of $3 \times 10^{8} / \mathrm{ml}$.

Platelet aggregation and plasma clotting. Platelet aggregation studies were performed on a microplate reader (21) using the SOFTmax Pro data acquisition software (Molecular Devices Corp., Sunnyvale, California, USA). A $5-\mu 1$ volume of ADP or thrombin solution at various concentrations was placed in each well, followed by addition of $95 \mu$ l of freshly prepared PRP for ADP studies or washed platelets for thrombin studies. To assess the effects of leptin on platelet aggregation, PRP was incubated with various concentrations of leptin for 5 minutes at room temperature before being added to the wells containing ADP or thrombin. Readings were taken every 30 seconds over a 5 -minute period at either 405-nm wavelength for washed platelets or at a 560-nm wavelength for PRP. All platelet aggregation studies were performed in triplicate and were repeated at least three times with similar results. Changes in light transmission over time were expressed as percentage of PPP light transmission, with transmission of untreated PRP serving as the zero standard. Graphs of percentage of light transmission versus time (aggregation traces) were constructed with standard software programs.

To perform clotting studies, human or mouse PPP was incubated with leptin $(100 \mathrm{ng} / \mathrm{ml})$ for 5 minutes at room temperature before addition of thrombin $(0.5$ $\mathrm{U} / \mathrm{ml}$ ). The sample was recalcinated with $2 \mathrm{mM} \mathrm{CaCl}_{2}$ immediately before the first reading of the microplate (wavelength, $560 \mathrm{~nm}$ ).

Statistical analysis. For continuous variables, differences between the medians were tested by the MannWhitney nonparametric test or by the Kruskal-Wallis test followed by the Dunn multiple comparisons test. To compare the thrombotic response of different mouse groups, mouse vessels that only transiently occluded or did not occlude completely after injury 
Table 1

Metabolic parameters of 6- to 8-week-old WT, ob/ob, and db/db mice

\begin{tabular}{lcccc}
\hline Genotype & $\begin{array}{c}\text { Body weight } \\
(\mathrm{g})\end{array}$ & $\begin{array}{c}\text { Serum glucose } \\
(\mathrm{mg} / \mathrm{dl})\end{array}$ & $\begin{array}{c}\text { Serum insulin } \\
(\mathrm{ng} / \mathrm{ml})\end{array}$ & $\begin{array}{c}\text { Serum leptin } \\
(\mathrm{ng} / \mathrm{ml})\end{array}$ \\
WT & $23.9 \pm 1.3$ & $209.4 \pm 14.8$ & $2.38 \pm 1.95$ & $2.02 \pm 0.98$ \\
$o b / o b$ & $43.5 \pm 3.5$ & $362.9 \pm 44.6$ & $10.29 \pm 13.76$ & not detected \\
$d b / d b$ & $41.4 \pm 1.3$ & $489.9 \pm 51.8$ & $21.3 \pm 16.81$ & $73.1 \pm 27.2$ \\
\hline
\end{tabular}

with $\mathrm{FeCl}_{3}$ were regarded as having times to thrombosis corresponding to the end of the flow-monitoring period (25 minutes). Qualitative variables were tested by the Fisher exact test. All statistical tests were two-sided with a $P$ value less than 0.05 indicating statistical significance.

\section{Results}

Thrombotic response to arterial injury is attenuated in leptindeficient obese mice. To determine whether the lack of functional leptin is associated with disorders of hemostatic function in vivo, we induced carotid artery injury in WT, $o b / o b$, and $d b / d b$ mice. As expected, the $o b / o b$ and $d b / d b$ mice were not only obese, but also were hyperglycemic and hyperinsulinemic (Table 1). Serum leptin levels were low in the WT mice, high in the $d b / d b$ mice, and undetectable in $o b / o b$ mice.

Figure 1 shows the characteristic flow patterns obtained when WT (Figure1a) and ob/ob (Figure 1, b-d) mice were subjected to arterial injury. The basal rate of carotid blood flow before induction of injury (shown as phase 1 ) was similar $(1.3 \pm 0.3 \mathrm{ml} / \mathrm{min})$ for the two genotypes. Arterial flow rapidly decreased, and the vessels remained occluded after the WT mice were injured (Figure 1a; approximate time to complete thrombosis, $8.5 \mathrm{~min}$ utes). In contrast, arterial flow in injured $o b / o b$ mice (Figure1, b and c) underwent repeated cycles of gradual reduction and then abrupt increases in blood flow. In some cases, the thrombi seemed to stabilize and remained occluded over the 25-minute interval (Figure 1b; approximate time to complete occlusion, 16 minutes). In other cases, stable thrombi never formed, and normal flow was observed at the end of the monitoring period (Figure 1c). Thus, thrombi forming in the obese mice were generally less stable and embolized more frequently than those of WT mice, and this frequently led to incomplete thrombotic occlusion of the injured vessel segment. Figure 2 shows that the median time to complete thrombotic arterial occlusion after injury was significantly prolonged in $o b / o b$ mice compared with their lean counterparts (median time, 12.5 vs. 8.6 minutes; $P<0.01)$. Importantly, 7 of 25 (28\%) of the $o b / o b$ mice only transiently occluded or did not completely occlude during the 25 -minute monitoring period as opposed to only 2 of $32(6 \%)$ of WT mice $(P=0.034)$. Furthermore, recanalization of thrombosed vessels occurred more rapidly in $o b / o b$ compared with WT mice (Figure 3a). For example, 17 of 25 (68\%) of the injured vessels from $o b / o b$ mice already were patent by the end of the 25-minute flowmonitoring period (including the seven vessels that did not completely occlude), as opposed to only 6 of 32 (19\%) in WT mice $(P<0.01)$. All $(100 \%)$ of the injured carotid arteries from $o b / o b$ mice were patent 24 hours after injury compared with $62 \%$ from WT animals.

Although not shown, no differences were observed between the two mouse genotypes with regard to the type or depth of anesthesia, the size of the carotid vessels, or the gross morphology of the platelet-rich thrombi and vessel wall when viewed with light microscopy (Masson's trichrome and Verhoeff's elastic stain). Perls' iron stain of injured vessels demonstrated that iron accumulated to a similar extent at the subendothelium and at the interface between the thrombus and the vessel wall in the two strains.

Administration of leptin rescues the thrombotic response of $o b / o b$ mice. If the lack of leptin was responsible for the unstable thrombi and prolonged times to thrombosis observed in $o b / o b$ mice, then administration of the hormone would be expected to restore the normal thrombotic response of these animals to $\mathrm{FeCl}_{3}$-induced vascular injury. To test this possibility, recombinant murine leptin was administered intraperitoneally to $o b / o b$ mice 30-45 minutes before induction of carotid

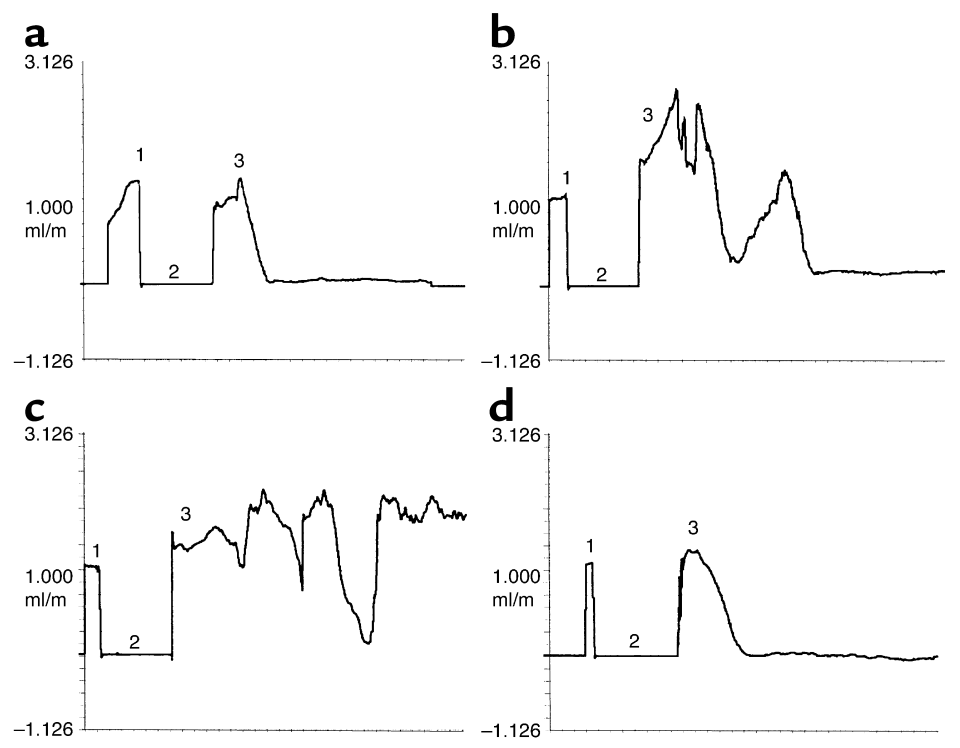

Figure 1

Characteristic flow patterns in response to $\mathrm{FeCl}_{3}$ injury. After recording baseline carotid blood flow (phase 1), ultrasound flow-monitoring was interrupted and the $\mathrm{FeCl}_{3}$-impregnated filter paper was placed on the adventitia of the vessel for 3 minutes (phase 2). The filter paper was removed, and the flow recording was continued (phase 3 ). (a) WT mouse, (b and c) ob/ob mice, (d) $o b / o b$ mouse 30 minutes after intraperitoneal injection of $0.6 \mathrm{mg} / \mathrm{kg}$ leptin. 


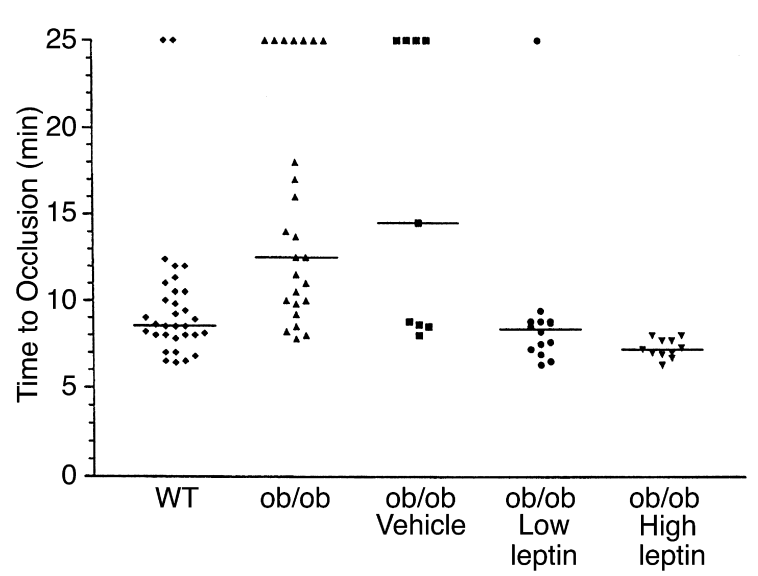

Figure 2

Times to thrombosis after arterial injury. $\mathrm{FeCl}_{3}$ was used to induce carotid artery injury in WT and $o b / o b$ mice. Displayed from left to right are the results obtained using WT mice, untreated $o b / o b$ mice, $o b / o b$ mice injected with sterile water (Vehicle), and $o b / o b$ mice after intraperitoneal administration of either $0.06 \mathrm{mg} / \mathrm{kg}$ (Low leptin) or $0.6 \mathrm{mg} / \mathrm{kg}$ (High leptin) body weight. The horizontal lines represent the median of the displayed values in each group. For statistical analysis, mice that only transiently occluded or did not occlude completely after injury are represented at the top of the graph as having times to thrombosis that correspond to the end of the flow-monitoring period (25 minutes).

artery injury (Figure 2). In this experiment, the control group was treated with vehicle alone $(0.2 \mathrm{ml}$ sterile water). A second, or low-dose group, received 0.06 $\mathrm{mg} / \mathrm{kg}$ leptin (i.e., $2.5-3.0 \mu \mathrm{g}$ per mouse), while a third, or high-dose, group received $0.6 \mathrm{mg} / \mathrm{kg}(25-32 \mu \mathrm{g}$ leptin per mouse). The investigator performing these experiments did not know the identity of the injected substance. Plasma leptin levels at the end of the 25minute flow-monitoring period were undetectable in vehicle-treated animals, $45.4 \pm 30.4 \mathrm{ng} / \mathrm{ml}$ in the lowdose group, and $761 \pm 185 \mathrm{ng} / \mathrm{ml}$ in the high-dose group (not shown).

As shown in Figure 2, treatment of $o b / o b$ mice with the low concentration of leptin decreased the median time to thrombosis from 12.5 minutes to $9.2 \mathrm{~min}$ utes $(P<0.01)$. This time is similar to that of WT mice (8.6 minutes; $P=\mathrm{NS}$ ). The higher dose of leptin had an even more pronounced effect, decreasing the median time to thrombosis to only 7.3 minutes. This time was not only significantly shorter than that of untreated $o b / o b$ mice $(P<0.001)$, but also was shorter than that of WT mice $(P<0.05)$. Importantly, all $(100 \%)$ of the carotid vessels of the $o b / o b$ mice completely occluded after injury in the high-dose group, as compared with 18 of 25 vessels $(72 \%)$ in the untreated and five of nine $(56 \%)$ in the vehicle-treated mice ( $P=0.076$ and 0.026 , respectively). Moreover, the high dose of leptin stabilized the thrombi formed in $o b / o b$ mice in response to $\mathrm{FeCl}_{3}$ (compare Figure $1 \mathrm{~d}$ with $\mathrm{b}$ and $\mathrm{c}$ ). Thus, intraperitoneal administration of leptin corrected the thrombotic response of $o b / o b$ mice to vascular injury, essentially restoring the phenotype of WT mice. The proportion of patent vessels 25 minutes after injury was also significantly lower in the leptin-treated $o b / o b$ mice compared with the untreated $o b / o b$ animals (Figure $3 \mathrm{~b} ; P<0.05$ for both comparisons), and only slightly higher than that in WT mice $(P=\mathrm{NS})$.

Leptin enhances platelet aggregation in vitro. Platelets recently were shown to express the long form of the leptin receptor (18). Thus, we hypothesized that leptin altered the thrombotic response of the $o b / o b$ mice to injury (Figures 1-3) by affecting platelet function. To investigate this possibility, we studied the effects of leptin on platelet aggregation in vitro. Although leptin alone had no effect on the aggregation of murine platelets (Figure $4 \mathrm{a}$; see 0 concentration of ADP), the presence of leptin $(100 \mathrm{ng} / \mathrm{ml})$ significantly enhanced the response of PRP from $o b / o b$ mice to ADP ( 0.5 and $1.0 \mu \mathrm{M}$; Figure 4a). Leptin had similar effects on PRP from WT animals (Figure 4b), except that it appeared to potentiate platelet aggregation at even lower concentrations of ADP (a concentration of $0.1 \mu \mathrm{M}$ ). Importantly, leptin also dose dependently enhanced the aggregation of human PRP in response to ADP and of washed human platelets in response to thrombin (not shown). For example, the maximal increase in light transmission when human PRP was treated with $0.1 \mu \mathrm{M}$ ADP was significantly higher in the presence of leptin $(100 \mathrm{ng} / \mathrm{ml})$ than in its absence $(34.5 \% \pm 0.6 \%$ vs. $17.9 \%$ $\pm 0.2 \% ; P<0.001)$. Similarly, light transmission from washed human platelets incubated in the presence of $0.1 \mathrm{U} / \mathrm{ml}$ thrombin increased by $39.9 \% \pm 0.4 \%$ after preincubation with leptin $(100 \mathrm{ng} / \mathrm{ml})$ compared with $20.3 \% \pm 0.7 \%$ in the absence of the hormone $(P<0.001)$. The clotting times of recalcified murine or human PPP in response to thrombin $(0.5 \mathrm{U} / \mathrm{ml})$ were not affected by the addition of leptin (not shown), suggesting that the

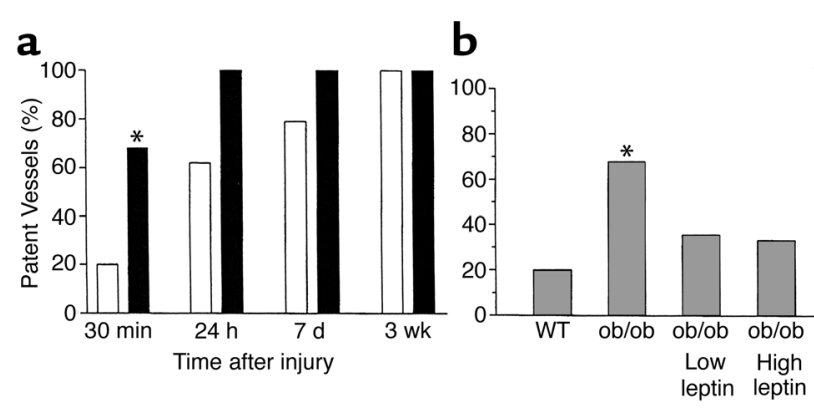

Figure 3

Times for restoration of flow (patency) after arterial injury. (a) Carotid patency rates in WT versus $o b / o b$ mice at various times after injury. Open bars represent WT mice and filled bars ob/ob mice. Number of animals at 25 minutes: $32 \mathrm{WT}$ and $25 \mathrm{ob} / \mathrm{ob}$ mice; number at 24 hours, 7 days, and 3 weeks: six animals per genotype per time point. (b) The effects of exogenous leptin administration on the proportion of patent vessels 30 minutes after injury. Results from WT $(n=32)$ and untreated $o b / o b$ mice $(n=25)$ are compared with those from $o b / o b$ mice that received low $(0.06 \mathrm{mg} / \mathrm{kg} ; n=14)$ and high $(0.6$ $\mathrm{mg} / \mathrm{kg} ; n=11$ ) doses of leptin intraperitoneally $30-45$ minutes before injury. ${ }^{*} P<0.01$ for the difference between WT and untreated $o b / o b$ mice at 25 minutes. 

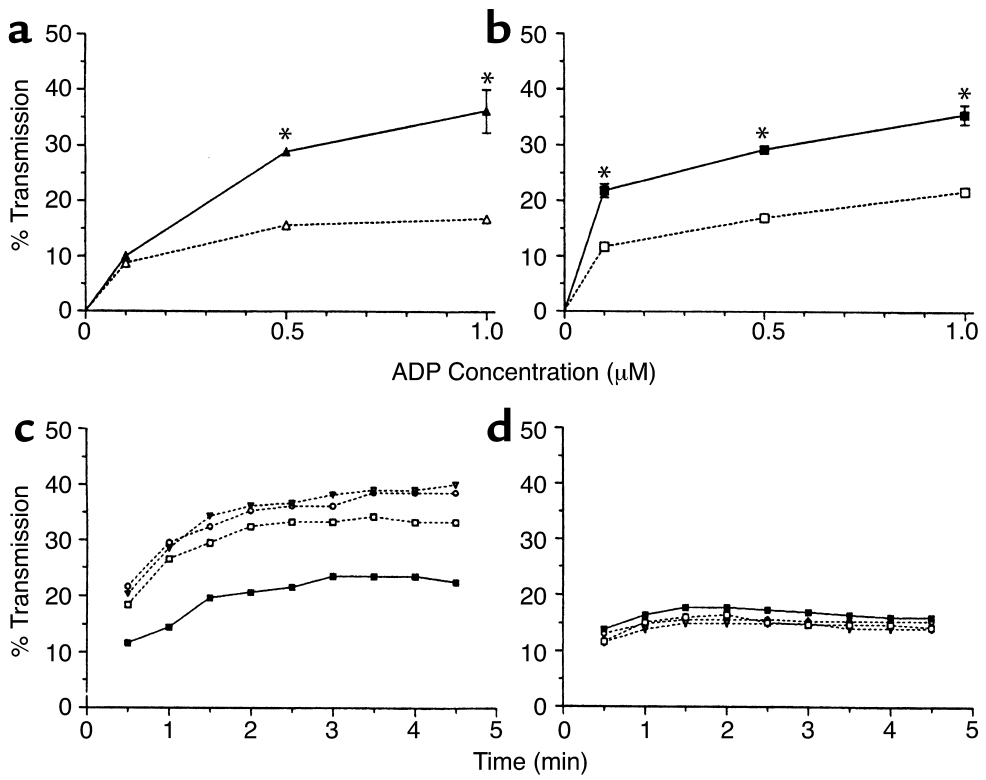

\section{Figure 4}

Leptin promotes murine platelet aggregation in response to ADP. In vitro aggregation studies of mouse PRP $\left(3 \times 10^{8}\right.$ platelets $\left./ \mathrm{ml}\right)$ were performed using a microplate reader. Displayed are the mean values \pm 1 SD from measurements performed in triplicate. PRP from $o b / o b(\mathbf{a})$ and WT (b) mice was stimulated by the addition of increasing concentrations of ADP in the absence (dashed lines) and presence (continuous lines) of $100 \mathrm{ng} / \mathrm{ml}$ leptin, respectively. ${ }^{*} P<0.001$ for the aggregation in the presence versus absence of leptin. (c and d) Effects of leptin on the aggregation of platelets from $o b / o b(\mathbf{c})$ and $d b / d b$ (d) mice stimulated with $0.5 \mu \mathrm{M}$ ADP. The continuous lines represent the aggregation trace of PRP in response to $0.5 \mu \mathrm{M}$ ADP alone (filled squares). The dashed lines represent platelet aggregation induced by the same concentration of ADP after preincubation with 10 (open squares), 100 (triangles), and 500 (circles) $\mathrm{ng} / \mathrm{ml} \mathrm{leptin}$, respectively.

effect of leptin was platelet specific. Figure $4 c$ shows that the effect of leptin on murine platelet function is dose dependent. In these experiments, the ADP $(0.5$ $\mu \mathrm{M})$ aggregation studies were repeated in the presence of increasing concentrations of leptin. Low concentrations of leptin $(10 \mathrm{ng} / \mathrm{ml})$ were able to enhance the aggregation of platelets from $o b / o b$ mice. The effect was more pronounced at $100 \mathrm{ng} / \mathrm{ml}$, but did not increase further at $500 \mathrm{ng} / \mathrm{ml}$. The aggregation of human platelets in response to ADP (not shown) also was increased by the higher concentrations of leptin (100 or $500 \mathrm{ng} / \mathrm{ml}$ ), but not by the lower dose (10 $\mathrm{ng} / \mathrm{ml} \mathrm{leptin)}$.
The effect of leptin on platelet aggregation and thrombosis is mediated by the leptin receptor. To determine whether the effects of leptin on platelet function and thrombosis were mediated by the long form of its receptor (22), we studied the effects of leptin on the ADP $(0.5 \mu \mathrm{M})$ response of PRP from $d b / d b$ mice (i.e., leptin-receptor deficient; ref. 23) (Figure 4d). In contrast to the results with platelets from $o b / o b$ (Figure 4, a and c) and WT (Figure 4b) mice, leptin had no effect on ADPinduced aggregation of $d b / d b$ mouse platelets, even at high concentrations (Figure 4d). These results were confirmed in vivo by examining the thrombotic response of $d b / d b$ mice. Table 1 shows the body weight as well as the serum glucose, insulin, and leptin levels of these mice. As demonstrated in Figure 5 , the time to thrombotic occlusion after arterial injury was longer in $d b / d b(12.9$ minutes) than in WT (8.6 minutes) mice $(P<0.01)$. Despite the fact that $d b / d b$ mice have relatively high serum leptin levels (i.e., $73.1 \pm 27.2 \mathrm{ng} / \mathrm{ml}$; Table 1 ), their median time to complete thrombosis after injury was indistinguishable from that of leptin-deficient $o b / o b$ mice (displayed in Figure 2). Moreover, although leptin corrected the thrombotic response of the $o b / o b$ mice, it had no effect on the response of $d b / d b$ mice (Figure 5), even though these mice achieved serum leptin levels of $555 \pm 450 \mathrm{ng} / \mathrm{ml}$. These serum leptin concentrations in the treated $d b / d b$ mice were 12 -fold higher than those achieved when the low dose of leptin was administered to $o b / o b$ mice. This low dose completely corrected the thrombotic response of $o b / o b$ mice (Figure 2).

Carotid artery injury also was induced in WT mice pretreated with leptin as above. Plasma leptin levels increased from approximately $2 \mathrm{ng} / \mathrm{ml}$ (Table 1 ) to 365 $\pm 202 \mathrm{ng} / \mathrm{ml}$ in this group at the end of the flow-monitoring period (not shown). The median time to occlu-

\section{Figure 5}

Leptin does not correct the abnormal thrombotic response of $d b / d b$ mice to injury. Compared from left to right are the times to complete thrombotic occlusion after injury in WT and $d b / d b$ mice pretreated with either vehicle or leptin. The vehicle (sterile $\left.\mathrm{H}_{2} \mathrm{O}\right)$ and leptin $(0.6$ $\mathrm{mg} / \mathrm{kg}$ ) were administered intraperitoneally 30 minutes before injury. The horizontal lines represent the median of the displayed values in each group. For statistical analysis, mice that did not completely occlude or only transiently occluded are represented at the top of the graph as having times to thrombosis that correspond to the end of the flow-monitoring period ( 25 minutes).

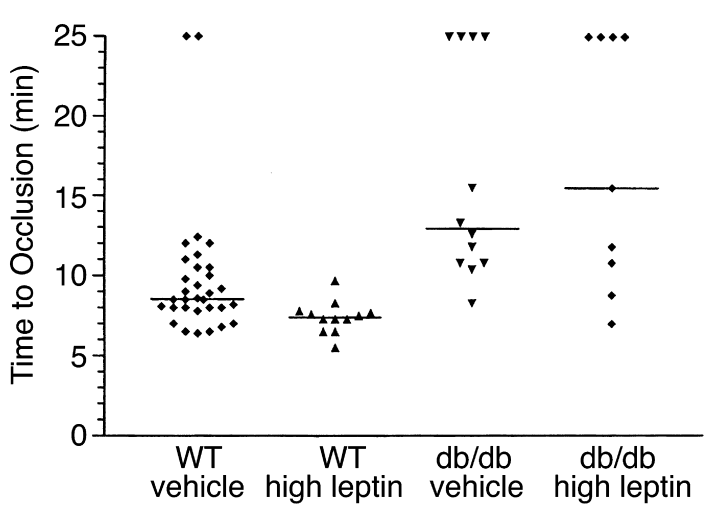


sion after injury was slightly but significantly shortened in these animals compared with untreated WT mice (7.4 vs. 8.6 minutes; $P=0.004)$, and all vessels remained completely occluded over the 25 -minute interval.

\section{Discussion}

The widespread assumption that obesity may be associated with a systemic prothrombotic state is supported primarily by observations showing that circulating levels of coagulation factor VII and of the antifibrinolytic molecule plasminogen activator inhibitor type 1 (PAI-1) are increased in obese, insulinresistant individuals $(4,24-26)$. Similar findings for PAI-1 were obtained in the $o b / o b$ mouse (27), which exhibits many of the phenotypic features of human obesity, including aspects of the metabolic syndrome (7). In addition to having elevated circulating levels of PAI-1 and increased PAI-1 gene expression in the adipose tissue, these mice also revealed increased expression of the procoagulant molecule, tissue factor, in the adipose tissue (28). Taken together, these observations in the mouse suggest that both impaired fibrinolysis and enhanced coagulation may contribute to hemostatic disorders in obesity. Based on these findings, we predicted that $o b / o b$ mice would have a shortened time to injury-induced thrombosis compared with WT mice. However, the in vivo studies reported here show that $o b / o b$ mice are associated with an attenuated, rather than enhanced, thrombotic response to $\mathrm{FeCl}_{3}$-induced arterial injury compared with lean (WT) controls. This finding was unexpected and suggests that the association between hemostatic function and obesity involves additional factor(s) besides those directly related to the coagulation or fibrinolytic systems.

The phenotype of the $o b / o b$ mouse results from the absence of functional leptin (5), the hormone known to play a crucial role in the pathogenesis of obesity. Here we show that the absence of leptin in $o b / o b$ mice (Figure 1) and of the leptin receptor in $d b / d b$ mice (Figure 5), results in the formation of thrombi that are very unstable compared with the thrombi formed when WT mice are injured (Figure 1). This instability not only contributes to the prolonged times to thrombosis (Figure 2) and increased number of vessels that do not permanently occlude (i.e., the "outliers" seen in Figures 2 and 5), but also results in the increased rate of patency of these mice (Figure 3). Since injection of leptin into $o b / o b$ mice corrected all of these defects (Figures 1-3), these abnormal phenotypes appear to be related and part of a continuum. In this regard, the data in Figures 2 and 5 would seem to suggest that there are two distinct populations of mice in each group (i.e., those that completely occlude after injury and those outliers that do not). However, closer examination reveals that this is probably not the case and again suggests that the two populations represent different parts of a continuum of abnormal thrombotic reactions that result from the instability of their thrombi. This continuum includes those vessels that occlude and remain completely blocked (i.e., no flow) over the 25-minute period (Figure 1a); those that occlude and embolize once or twice, but become completely occluded after that (Figure 1b); and those that only transiently occlude and are patent at 25 minutes (Figure 1c). Although not shown, this latter group includes the vessels from injured mice whose thrombi are so unstable that flow never decreases more than $10-20 \%$ over the interval. It is not clear why some of the mice are patent at 25 minutes and others are not. However, this is a population study, and individual differences in stress levels, degree of anesthesia, etc., are to be expected and may contribute to these differences in the response to injury.

The results of the present study also provide evidence that leptin may affect thrombosis in vivo by modulating platelet function. Thus, addition of leptin had no effect on the clotting time of recalcified PPP, suggesting that the platelet, and not a plasma component, is the target of leptin's effects on hemostasis. Moreover, the in vivo carotid injury studies show that leptin is necessary for the formation of stable thrombi (Figures 1-3), while the in vitro studies demonstrate that leptin promotes the aggregation of murine and human platelets (Figure 4). However, direct comparison of Figures 1 and 4 suggests that the instability of arterial thrombi in $o b / o b$ mice (Figure 1, $\mathrm{b}$ and c) is not simply the result of a defect in platelet aggregation. In fact, platelets from $o b / o b$ mice aggregate just as well to ADP as do WT platelets (Figure 4; compare parts a and b). Thus, while leptin clearly stimulates platelet aggregation, the absence of leptin does not appear to alter the ability of platelets to respond to normal stimuli (e.g., ADP). Despite this, the absence of leptin did result in the formation of unstable thrombi (Figure 1). These thrombi initially grew as revealed by repeated decreases in flow (Figure $1, b$ and $c$ ), but then rapidly embolized (restoration of flow) under high shear. This behavior is very reminiscent of the behavior of thrombi formed in fibrinogendeficient mice (29). This observation suggests that the binding of fibrinogen/fibrin to platelets and/or the vessel wall may also be compromised in mice lacking leptin or its receptor.

It is interesting to note that leptin alone did not induce platelet aggregation, but only potentiated the response of platelets to agonists such as ADP and thrombin. In both $o b / o b$ and WT mice, platelet aggregation was enhanced by preincubation with leptin at the lowest concentration tested $(10 \mathrm{ng} / \mathrm{ml})$, but the effect was more pronounced at higher doses (e.g., 100 $\mathrm{ng} / \mathrm{ml}$ ). In contrast, the aggregation of human platelets was enhanced only by the higher concentrations of leptin (100 and $500 \mathrm{ng} / \mathrm{ml}$ ), in agreement with a previous report (18). It should be noted, however, that the aggregation of some ADP-treated human platelet preparations was not enhanced by the addition of leptin. Whether this lack of response 
resulted from the presence of high levels of endogenous leptin $(10,11)$ or from some other physiological difference in the donors remains to be determined. Importantly, leptin had no effect on the aggregation of platelets from $d b / d b$ mice (Figure $4 d$ ), and the attenuated thrombotic response of $d b / d b$ mice to arterial injury was not corrected by the administration of high doses of leptin (Figure 5). In the $d b / d b$ mouse, abnormal splicing of the long form of the leptin receptor results in premature termination of its intracellular domain $(16,23)$. This mutation prevents leptin signaling and leads to a metabolic and behavioral phenotype virtually indistinguishable from that of the leptin-deficient $o b / o b$ mouse (7). Since platelets express the long form of the leptin receptor (18), our experiments indicate that this receptor is required to mediate the effects of leptin on platelet function and thrombosis.

The actual mechanism by which the binding of leptin to its receptor on platelets promotes platelet aggregation and arterial thrombosis in vivo remains to be determined. The long form of the leptin receptor is a member of the hematopoietic growth factor or class I cytokine receptor superfamily $(22,30)$. Receptors in this class mediate intracellular signal transduction via activation of receptor-associated tyrosine kinases of the Janus family (JAKs) and subsequent tyrosine phosphorylation of members of the signal transducers and activators of transcription family $(31,32)$. Interestingly, the addition of leptin to human platelets induced the phosphorylation of several platelet proteins (18). Taken together, these results suggest that leptin deficiency results in a defect in the signaling pathway that regulates platelet activation. It was suggested previously that JAK phosphorylation induced by activated cytokine receptors may enhance platelet aggregation by modulating $\alpha \operatorname{IIb} \beta 3$ integrin function (33). While interesting, this hypothesis remains to be confirmed. It is possible that activation of the leptin receptor might enhance platelet aggregation in response to ADP in a way resembling the effects of thrombopoietin (i.e., by priming platelets for activation by multiple agonists; ref. 33). In fact, the leptin receptor and the thrombopoietin receptor $\mathrm{c}-\mathrm{mpl}$ belong to the same family of cytokine receptors $(34,35)$. Finally, it is interesting to note that inactivation of the Gas 6 gene in mice also protected them from injury-induced thrombosis (36). Moreover, the addition of Gas 6, a member of the vitamin $\mathrm{K}$-dependent protein family (37), potentiated platelet aggregation and secretion in response to ADP and other platelet agonists. Like leptin, Gas 6 alone had no effect on platelet aggregation. Angelillo-Scherrer et al. (36) point out that platelets from the Gas 6-deficient mice resemble platelets from patients with primary signal transduction defects (38). The similarity of platelets from leptin-deficient $o b / o b$ mice and Gas 6-deficient mice is again consistent with the hypothesis that platelets from $o b / o b$ mice have a defect in leptin signaling.
In conclusion, the results of the present study reveal a novel biological role for leptin in the regulation of hemostasis and suggest a possible direct link between leptin and the pathogenesis of acute atherothrombotic events in obesity. It is important to emphasize that the thrombotic response of $o b / a b$ mice was enhanced with the lowest leptin dose employed $(0.06 \mathrm{mg} / \mathrm{kg})$, a dose that resulted in serum leptin levels in the range of $20-100 \mathrm{ng} / \mathrm{ml}$. These levels correspond to leptin concentrations in the circulation of obese humans $(10,11)$, raising the possibility that platelets from such individuals are hypersensitized (primed) to respond to normal platelet agonists. These concentrations of leptin are considerably lower than the serum levels recently reported in a preliminary trial that examined the weight-reducing effects of leptin administration on obese and lean individuals (39). Thus, these preliminary studies with the mouse, when considered with our studies and those of others (18) showing that leptin also promotes the aggregation of human platelets, suggest that large-scale clinical studies using high concentrations of leptin should proceed with caution. Obviously, further studies are required to define the exact mechanisms and pathways mediating the effects of leptin on platelet aggregation and thrombosis. Moreover, the clinical implications of these findings need to be examined in detail, particularly with regard to the atherothrombotic risk of obese individuals and the potential hazards of long-term leptin administration as a weight-reducing treatment.

\section{Acknowledgments}

We thank A. Palestini for her excellent secretarial support, and S. Shattil, A. Obergfell, L. Miles, R. Aimes, and R. Schleef for helpful discussions. This work received the Knoll William Harvey Prize (2001) and was supported by a grant from Boehringer Ingelheim to S. Konstantinides, a grant from the Deutsche Forschungsgemeinschaft (German Research Association, DFG \#Scha 808/1-1) to K. Schäfer, and by NIH grants HL-47819 and HL-31950 to D.J. Loskutoff. This is Scripps Research Institute manuscript number 14021-VB.

1. Laakso, M. 1999. Hyperglycemia and cardiovascular disease in type 2 diabetes. Diabetes. 48:937-942.

2. Howard, G., et al. 1996. Insulin sensitivity and atherosclerosis. The insulin resistance atherosclerosis study (IRAS) investigators. Circulation. 93:1809-1817.

3. Fuster, V., Badimon, L., Badimon, J.J., and Chesebro, J.H. 1992. The pathogenesis of coronary artery disease and the acute coronary syndromes. N. Engl. J. Med. 326:310-318.

4. Loskutoff, D.J., and Samad, F. 1998. The adipocyte and hemostatic balance in obesity: studies of PAI-1. Arterioscler. Thromb. Vasc. Biol. 18:1-6.

5. Zhang, Y., et al. 1994. Positional cloning of the mouse obese gene and its human homologue. Nature. 372:425-432.

6. Friedman, J.M., and Halaas, J.L. 1998. Leptin and the regulation of body weight in mammals. Nature. 395:763-770.

7. Friedman, J.M., and Leibel, R.L. 1992. Tackling a weighty problem. Cell. 69:217-220.

8. Pelleymounter, M.A., et al. 1995. Effects of the obese gene product on body weight regulation in $o b / o b$ mice. Science. 269:540-543.

9. Montague, C.T., et al. 1997. Congenital leptin deficiency is associated with severe early-onset obesity in humans. Nature. 387:903-908.

10. Considine, R.V., et al. 1996. Serum immunoreactive-leptin concentrations in normal-weight and obese humans. N. Engl. J. Med. 334:292-295. 
11. Maffei, M., et al. 1995. Leptin levels in human and rodent: measurement of plasma leptin and $o b$ RNA in obese and weight-reduced subjects. Nat. Med. 1:1155-1161.

12. Lord, G.M., et al. 1998. Leptin modulates the T-cell immune response and reverses starvation-induced immunosuppression. Nature. 394:897-901.

13. Sierra-Honigmann, M.R., et al. 1998. Biological activation of leptin as an angiogenic factor. Science. 281:1683-1686.

14. Ducy, P., et al. 2000. Leptin inhibits bone formation through a hypothalamic relay: a central control of bone mass. Cell. 100:197-207.

15. Chehab, F.F., Lim, M.E., and Lu, R. 1996. Correction of the sterility defect in homozygous obese female mice by treatment with the human recombinant leptin. Nat. Genet. 12:318-320.

16. Lee, G.H., et al. 1996. Abnormal splicing of the leptin receptor in diabetic mice. Nature. 379:632-635.

17. Tartaglia, L.A., et al. 1995. Identification and expression cloning of a leptin receptor, OB-R. Cell. 83:1263-1271.

18. Nakata, M., Yada, T., Soejima, N., and Maruyama, I. 1999. Leptin promotes aggregation of human platelets via the long form of its receptor. Diabetes. 48:426-429.

19. Konstantinides, S., Schäfer, K., Thinnes, T., and Loskutoff, D.J. 2001. Plasminogen activator inhibitor- 1 and its cofactor vitronectin stabilize arterial thrombi following vascular injury in mice. Circulation. 103:576-583.

20. Fay, W.P., Parker, A.C., Ansari, M.N., Zheng, X., and Ginsburg, D. 1999. Vitronectin inhibits the thrombotic response to arterial injury in mice. Blood. 93:1825-1830.

21. Fratantoni, J.C., and Poindexter, B.J. 1990. Measuring platelet aggregation with microplate reader. A new technical approach to platelet aggregation studies. Am. J. Clin. Pathol. 94:613-617.

22. Tartaglia, L.A. 1997. The leptin receptor. J. Biol. Chem. 272:6093-6096.

23. Chen, H., et al. 1996. Evidence that the diabetes gene encodes the leptin receptor: identification of a mutation in the leptin receptor gene in $d b / d b$ mice. Cell. 84:491-495.

24. Festa, A., et al. 1999. Relative contribution of insulin and its precursors to fibrinogen and PAI-1 in a large population with different stages of glucose tolerance. The insulin resistance atherosclerosis study (IRAS). Arterioscler. Thromb. Vasc. Biol. 19:562-568.

25. Kruszynska, Y.T., Yu, J.G., Olefsky, J.M., and Sobel, B.E. 2000. Effects of troglitazone on blood concentrations of plasminogen activator inhibitor 1 in patients with type 2 diabetes and in lean and obese normal subjects. Diabetes. 49:633-639.
26. Juhan-Vague, I., Alessi, M.C., and Morange, P.E. 2000. Hypofibrinolysis and increased PAI-1 are linked to atherothrombosis via insulin resistance and obesity. Ann. Med. 32:78-84.

27. Samad, F., and Loskutoff, D.J. 1996. Tissue distribution and regulation of plasminogen activator inhibitor-1 in obese mice. Mol. Med. 2:568-582.

28. Samad, F., Pandey, M., and Loskutoff, D.J. 1998. Tissue factor gene expression in the adipose tissues of obese mice. Proc. Natl. Acad. Sci. USA. 95:7591-7596.

29. Ni, H., et al. 2000. Persistence of platelet thrombus formation in arterioles of mice lacking both von Willebrand factor and fibrinogen. J. Clin. Invest. 106:385-392.

30. White, D.W., Kuropatwinski, K.K., Devos, R., Baumann, H., and Tartaglia, L.A. 1997. Leptin receptor (OB-R) signaling. Cytoplasmic domain mutational analysis and evidence for receptor homo-oligomerization. J. Biol. Chem. 272:4065-4071.

31. Heldin, C.H. 1995. Dimerization of cell surface receptors in signal transduction. Cell. 80:213-223.

32. Kishimoto, T., Taga, T., and Akira, S. 1994. Cytokine signal transduction. Cell. 76:253-262.

33. Oda, A., et al. 1996. Thrombopoietin primes human platelet aggregation induced by shear stress and by multiple agonists. Blood. 87:4664-4670.

34. Skoda, R.C., et al. 1993. Murine c-mpl: a member of the hematopoietic growth factor receptor superfamily that transduces a proliferative signal. EMBO J. 12:2645-2653.

35. Vigon, I., et al. 1992. Molecular cloning and characterization of MPL, the human homolog of the v-mpl oncogene: identification of a member of the hematopoietic growth factor receptor superfamily. Proc. Natl. Acad. Sci. USA. 89:5640-5644.

36. Angelillo-Scherrer, A., et al. 2001. Deficiency or inhibition of Gas6 causes platelet dysfunction and protects mice against thrombosis. Nat. Med. 7:215-221.

37. Manfioletti, G., Brancolini, C., Avanzi, G., and Schneider, C. 1993. The protein encoded by a growth arrest-specific gene (gas6) is a new member of the vitamin K-dependent proteins related to protein $\mathrm{S}$, a negative coregulator in the blood coagulation cascade. Mol. Cell. Biol. 13:4976-4985.

38. Rao, A.K., and Gabbeta, J. 2000. Congenital disorders of platelet signal transduction. Arterioscler. Thromb. Vasc. Biol. 20:285-289.

39. Heymsfield, S.B., et al. 1999. Recombinant leptin for weight loss in obese and lean adults: a randomized, controlled, dose-escalation trial. JAMA. 282:1568-1575. 